\title{
Ansiedade e depressão: o mundo da prática docente e o adoecimento psíquico
}

Rodney Querino Ferreira-Costa. Faculdade Anhanguera de São José dos Campos

Nelson Pedro-Silva. Universidade Estadual Paulista

\section{Resumo}

O adoecimento mental do trabalhador tornou-se objeto de estudos na atualidade, considerando os seus efeitos negativos na economia mundial e nas relações interpessoais. Por esta razão, foram analisados os níveis de ansiedade/depressão de 163 docentes que lecionavam no Ensino Básico da rede pública estadual de uma cidade paulista. A obtenção dos dados foi realizada por meio das escalas Beck Anxiety Inventory e Beck Depression Inventory, questionários sobre dados sociodemográficos e atinentes à satisfação laboral. Os resultados indicaram que $58 \%$ dos sujeitos demonstravam sinais de adoecimento mental, e $27 \%$ deles apresentaram sintomas condizentes ao quadro de transtorno de ansiedade e/ou depressão. Concluiu-se que os professores têm se desgastado mentalmente em demasia, em um momento social efêmero, de imposição da dinâmica trabalhista de curto prazo, flexível, competitivo e de produtividade. Esses aspectos levam os professores a adoecer mentalmente, desestimulando-os a estabelecer vínculos profundos com a sua função e com os estudantes.

Palavras-chave: ansiedade; depressão; saúde mental; professores.

\begin{abstract}
Anxiety and depression: the world of teaching work and psychological exhaustion. The worker's mental illness has become the object of studies nowadays, considering its negative effects in the world economy and in the interpersonal relations. Thereat, analyzed the anxiety/depression levels of 163 teachers who taught in public school of a city of São Paulo state. Beck Anxiety Inventory and Beck Depression Inventory were used to obtain the data, as well as questionnaires on sociodemographic and occupational satisfaction data. The results indicated that $58 \%$ of the participants were psychologically ill, $27 \%$ of whom presented symptoms consistent with anxiety and/or depression. It is concluded that teachers have become too mentally worn out, in an ephemeral social time, of imposition of short-term work dynamic, flexible, competitive and productivity. These aspects have made them mentally ill and discouraged them from establish affective bonds with their job and students.
\end{abstract}

Keywords: anxiety; depression; mental health; teachers.

\section{Resumen}

Ansiedad y depresión: el mundo de la práctica del professor y el agotamiento psíquico. La enfermedad mental del trabajador se convertióen objeto de estudios en la actualidad, considerando sus efectos negativos en la economía mundial y en las relaciones interpersonales. Por eso se analizaron los niveles de ansiedad y depresión de 163 docentes que trabajavan en escuelas públicas de una ciudad del Estado de São Paulo. Para la obtención de los datos, se utilizaron las escalas Beck, así como cuestionarios sobre datos sociodemográficos y relativos a la satisfacción laboral. Los resultados indicaron que $58 \%$ de los sujeitos estaban psicológicamente enfermos, siendo que $27 \%$ de ellos presentaron síntomas concordantes de ansiedad o de depresión. Se concluyó que los profesores se han desgastado mentalmente en demasía, en un momento social efímero, de imposición de la dinámica laboral a corto plazo, flexible, competitiva y de productividad. Estos aspectos los enfermaron mentalmente y los desalentaron a establecer vínculos con su función y con los estudiantes.

Palabras clave: ansiedad; depresión; salud mental; profesores. 
Os professores estão mentalmente adoecidos? Tal indagação começou a ser construída à medida que os pesquisadores tiveram contato com os docentes, em decorrência do seu exercício profissional como psicólogos escolares de uma rede pública de ensino e como psicoterapeutas em um ambulatório de saúde mental. Esses profissionais, usualmente, compartilhavam com os estudiosos o sofrimento vivenciado, a ponto de terem suas vidas pessoais e laborais prejudicadas. Embora tal sensação seja inerente à existência do indivíduo, era perceptível que esses docentes estavam apresentando sinais de adoecimento.

Esta observação foi ao encontro de estudos feitos por pesquisadores e por organizações de classe dos docentes. Vários desses levantamentos apontaram que parte significativa dos professores apresentava sintomas de doença mental, além de esta ser a principal causa de afastamento do trabalho (Gasparini, Barreto, \& Assunção, 2006; E. P. Silva, 2015).

Em linhas gerais, para esses autores, as queixas eram as seguintes: a) baixos salários (Inocente, 2005; Simplício \& Andrade, 2011); b) indisciplina dos estudantes (Codo, 1999; Gasparini et al., 2006; Simplício \& Andrade, 2011; C. L. Souza et al., 2011); c) ações violentas praticadas por educandos e pais em relação aos docentes (Gasparini et al., 2006; Simplício \& Andrade, 2011); d) sobrecarga de funções, como a de organização dos materiais, elaboração das aulas e correções das lições e provas (Carraro, 2015; Codo, 1999; Elias, 2014; Ferreira et al., 2015; Reis, Carvalho, Araújo, Porto, \& Silvany-Neto, 2005; C. L. Souza., 2011); e) ambiente físico e materiais inadequados para o exercício da docência (Codo, 1999; Ferreira et al., 2015; Gasparini et al., 2006; E. P. Silva, 2015; C. L. Souza et al., 2011; J. C. Souza \& Costa, 2011); f) desvalorização social da profissão (Costa, 2014; Inocente, 2005; Simplício \& Andrade, 2011); g) ausência de união entre os educadores (E. P. Silva, 2015; Simplício \& Andrade, 2011; C. L. Souza et al., 2011); e h) falta ou dificuldade de diálogo com a direção e a coordenação pedagógica da escola (Carraro, 2015; Codo, 1999; Elias, 2014; Gasparini et al., 2006; Simplício \& Andrade, 2011).

É possível supor, em face das pesquisas, que a escola tem infringido demasiado desgaste mental em seus docentes - uma característica, segundo os pesquisadores, sempre presente nas ocupações que exigem contato direto e constante com a sua clientela. Desgaste é entendido aqui como a perda da capacidade potencial e/ou efetiva corporal e psíquica decorrente do processo de adaptação dos trabalhadores frente às demandas e interações decorrentes de suas funções
(Laurell \& Noriega, 1989; Seligmann-Silva, 2011). Uma das consequências desse desgaste é a manifestação de doenças mentais (Seligmann-Silva, 2011; Vicente, 2015).

Acrescenta-se as análises feitas sobre a sociedade atual por Bauman (1997), La Taille (2009), Sennett (2004, 2006, 2009), entre outros estudiosos. Estes observaram que o homem contemporâneo não possui tempo e disposição suficiente para satisfazer a todos os quesitos impostos, levando-o a ter uma "existência superficial" e, com efeito, a responder às novas sensações sem entusiasmo e profundidade.

Assim, indagou-se: os docentes, mesmo os altamente resilientes, não estavam adoecendo por causa da influência ideológica pela qual os media modelam a opinião pública (Adorno, Frenkel-Brunswik, Levinson, \& Sanford, 1950), cujo cerne é o individualismo, a flexibilidade, a efemeridade e os vínculos de curto prazo? Mudou algo na relação trabalho/trabalhador na atualidade, a ponto de esta interação levar ao adoecimento e ao empobrecimento das relações interpessoais, até com familiares e amigos íntimos?

Apesar de não ter feito estudos no campo da Educação, os aportes de Sennett (2004, 2006, 2009) auxiliam a entender as mudanças ocorridas, desde a década de 1990, no campo da ação educativa. Assim como Elias (2014), Pereira (2015) e R. R. D. Silva (2015), julga-se que o modelo social e econômico no qual as pessoas estão inseridas exerce influência considerável na concepção, nos conteúdos e na prática educativa adotada. Para Seligmann-Silva (2011), inclusive, "nas interseções entre processo de trabalho e processo saúde-doença, determinações de ordem sociopolítica e econômica passam a atuar" (p. 135).

Conforme Sennett (2009), as instituições subordinadas ao capitalismo pós-industrial caracterizam-se pela flexibilidade, no lugar da rotina burocrática rígida de outros tempos. Isso tem ocorrido porque as demandas atuais da sociedade estão influenciando as estruturas internas das organizações, em uma velocidade nunca antes vista; portanto, o trabalhador, para se manter competitivo, deve buscar a qualificação e a renovação, de modo constante, para não se tornar descartável (como os próprios produtos fabricados por ele e os serviços oferecidos).

A escola insere-se nessa realidade, quando sua prática dialoga com o discurso de formação de ativos, isto é, de potencialização do capital humano, nesses tempos efêmeros. Como aponta R. R. D. Silva (2015), "as práticas escolares precisam tornar-se úteis, divertidas 
e estimulantes, fazendo com que o educando aproxime-se da figura de um cliente" (p. 32). Por esta razão, avaliou-se que as agências educativas apresentavam potencial de adoecimento, independente do perfil do educando, pois o processo de construção dos sujeitos é mediado por esse novo modo de funcionar do capitalismo (Elias, 2014; Pereira, 2015; Silva, R. R. D., 2015).

Em meio às manifestações de adoecimento decorrentes do desgaste mental, Vicente (2015) destaca, entre outros, os transtornos ansiosos e depressivos. Segundo a $5^{\text {a }}$ Edição do Manual Diagnóstico e Estatístico de Transtornos Mentais (American Psychiatric Association, 2015), a depressão é uma doença do humor, cujos principais sintomas são tristeza e perda do interesse e do prazer na realização de quase todas as atividades, de forma diária e crônica, a ponto de impedir o sujeito de vivenciar sua existência adequadamente, amiúde não vendo mais sentido em viver. Os transtornos de ansiedade, por sua vez, decorrem de uma "desregulação" nos mecanismos psíquicos responsáveis pela identificação de estados vulneráveis a situações potenciais de perigo.

A propósito: E. P. Silva (2015) investigou os motivos de afastamento médico docente. Este verificou a prevalência dos transtornos ansiosos e de humor nos casos de doença mental. Anteriormente, Inocente (2005) já observara que a incidência de depressivos entre os educadores era maior do que na média nacional. Em ambos os estudos, a população pesquisada foi de docentes universitários. Apesar de existir vários estudos no campo da saúde mental a ter a escola como objeto de análise, ainda são escassos os que focam essas psicopatologias específicas, sobretudo tendo como sujeitos docentes da educação básica.

\section{Objetivos}

Com base nesses aspectos, o objetivo principal deste trabalho consistiu em verificar os níveis de sintomas ansiosos e depressivos em professores do Ensino Básico público.

Optou-se pelo estudo destas psicopatologias, pois, segundo dados da Organização Mundial de Saúde (OMS), a depressão foi apontada como o principal problema de saúde incapacitante. De acordo com as estimativas, até 2020 , a depressão e a ansiedade serão as doenças que mais afetarão a população mundial, depois das cardiovasculares (Dalgalarrondo, 2008).

Em relatório divulgado pelo mesmo órgão, o Brasil figurou como o país com maior proporção de ansiosos (9,3\%), equivalendo a 18,6 milhões de pessoas. Referente à depressão, 5,8\% sofriam dessa doença (11,5 milhões) (OMS, 2017).

Secundariamente, buscou-se: a) analisar se os referidos níveis eram dependentes de caracteres pessoais/profissionais; b) averiguar o grau de satisfação dos educadores no tocante ao seu trabalho e a relação deste com seus níveis de sintomas ansiosos e depressivos; c) verificar a proporção de docentes que estavam em atendimento de psicoterapia e faziam uso de medicação com função psicotrópica.

\section{Método}

Fez-se estudo epidemiológico de corte transversal. Esse modelo detém-se na incidência de certas patologias físicas/psíquicas em dada população e suas causas (Jacques, 2003).

\section{Sujeitos}

Participaram 163 docentes que atuavam nos Ensinos Fundamental e Médio da rede estadual de uma cidade de grande porte do Vale do Paraíba (SP). Desses participantes, 55 (33,7\%) trabalhavam em escolas de regime integral e 108 em regulares (66,3\%).

\section{Instrumentos}

Para a averiguação dos níveis de sintomas ansiosos e depressivos foram utilizadas as escalas Beck Depression Inventory (BDI) (Beck, Erbaugh, Mendelson, Mock, \& Ward, 1961) e Beck Anxiety Inventory (BAI) (Beck, Brown, Epstein, \& Steer, 1988), validadas para o Brasil por Cunha (2011). Essas escalas são do tipo autorrelato, compostas de 21 itens. No caso do BAl, o sujeito deve assinalar a intensidade com que sentiu tais sintomas na semana anterior à aplicação do inventário. No $\mathrm{BDI}$, cada item é formado por quatro frases, em que o inquirido deve indicar a asserção a descrever melhor como se percebeu nos últimos sete dias. Acrescenta-se que os pesquisadores optaram por essas escalas em razão da facilidade de manuseio pelos sujeitos.

Empregou-se, também, um questionário sociodemográfico, por meio do qual os sujeitos foram inquiridos sobre dados factuais (idade, sexo, etnia, estado civil, número de filhos, religião, formação acadêmica, disciplina ministrada, tempo de serviço, carga horária, entre outros aspectos). Igualmente, os sujeitos foram questionados acerca do uso de medicação com função psicotrópica, tratamento com médico psiquiatra e acompanhamento psicoterápico. 
Por fim, os sujeitos responderam a um questionário cujo objetivo era informar o grau de satisfação com o trabalho. O referido instrumento foi construído pelos autores com base no levantamento de variáveis julgadas produtoras de adoecimento psíquico nos docentes (Carraro, 2015; Costa, 2014; Elias, 2014; Ferreira et al., 2015; Gasparini et al., 2006; Inocente, 2005; E. P. Silva, 2015; Silveira, Reis, Santos, \& Borges, 2011; Simplício $\&$ Andrade, 2011; J. C. Souza \& Costa, 2011). Para cada questão, os sujeitos foram solicitados a escolher uma, entre as opções apresentadas: "muito satisfeito"; "satisfeito"; "pouco satisfeito"; "insatisfeito" e "não tenho opinião". Conforme levantamento bibliográfico feito, avaliaram-se os seguintes itens: a) estrutura física da escola; b) materiais pedagógicos; c) diálogo com a direção/coordenação; d) interação entre os docentes e destes com os demais funcionários; e) interesse dos alunos pelas disciplinas; f) respeito do alunado/ responsáveis para com o professor; g) interesse na vida escolar dos filhos; h) remuneração; i) tempo para preparo das aulas e veiculação do conteúdo programático e j) realização profissional.

Optou-se pela construção desse instrumento, pois os pesquisadores não encontraram na literatura investigada um questionário que mensurasse todos os itens propostos no estudo. Tal questionário foi submetido a pré-teste, cuja avaliação foi feita por professores que não foram sujeitos do estudo. Na sequência, procedeu-se a modificações relacionadas à linguagem, de tal maneira que os potenciais sujeitos compreendessem as questões feitas. Uma das sugestões feitas pelos participantes desse pré-teste referiu-se à separação do item atinente ao tempo para a realização das atividades pedagógicas em dois: a) tempo para a preparação das aulas e b) para veiculação dos conteúdos curriculares em sala de aula. Ao final, o instrumento passou por análise estatística, feita por especialista da área. O questionário elaborado possui boa consistência interna, apresentando alfa de Cronbach de 0,9773.

\section{Procedimentos}

Para obtenção e análise das informações (agosto e outubro de 2016), procedeu-se as seguintes etapas: a) contato com os diretores das escolas, com o fim de obter autorização para a coleta dos dados junto aos docentes. A direção, então, estipulou data para os pesquisadores participarem da Aula de Trabalho Pedagógico Coletivo; b) com os professores dispostos a colaborar, esclareceram-se os objetivos do estudo, entregou-se o Termo de Consentimento Livre e Esclarecido e, em seguida, os instrumentos, salientando que os pesquisadores estariam à disposição para dirimir dúvidas; c) após o preenchimento e devolução, foram feitos os agradecimentos; d) por fim, retornou-se às escolas para, coletivamente, prestar devolutiva aos sujeitos e proferir palestra sobre o tema; e) com os questionários respondidos, classificaram-se os níveis de sintomas ansiosos e depressivos, conforme os manuais das escalas BAI e $\mathrm{BDI}$;) em seguida, no mesmo artefato, arrolaram-se os dados atinentes aos fatores factuais; g) especificamente quanto às escalas de mensuração da ansiedade/ depressão, elas apresentam quatro opções de resposta. Sendo assim, no próprio instrumento, constava a alternativa que melhor se relacionava ao caso. As pontuações variam entre zero (ausente) e três pontos (severo). Finalizada a soma, coloca-se o sujeito na categoria correspondente à sua pontuação. Os sintomas das Escalas são divididos pela intensidade: mínimo, leve, moderado e grave. Cabe informar: não há consenso na literatura com relação à nota de corte para se definir se o sujeito apresenta sinais típicos de depressão/transtorno de ansiedade. Os valores sugeridos encontram-se entre 10 e 20 pontos (Cunha, 2011; Inocente, 2005; Gomes \& Oliveira, 2013; Oliveira et al., 2011). Assim, no presente estudo, considerou-se como nota de corte a pontuação igual ou acima de 20 pontos, ou seja, que apresentaram quantidade correspondente aos níveis moderado e grave. Porém, os classificados no nível "leve" já sugerem sinais de adoecimento psíquico, isto é, os sujeitos podem estar no princípio desses transtornos ou apresentam outra doença psiquiátrica igualmente manifestadora de sintomas ansiosos e/ou depressivos. Importa informar que a pesquisa se limitou a investigar no público-alvo a incidência de sintomas comuns encontrados em tais psicopatologias. Contudo, para um diagnóstico, ou seja, informar de maneira precisa a existência de uma doença e qual sua natureza, seria necessária a análise de cada sujeito individualmente, bem como uma investigação aprofundada de variáveis que vão além da mera descrição dos sintomas; $h$ ) feita a categorização, analisou-se a proporção de docentes que apresentaram esses sintomas, sua relação com os dados sociodemográficos e o grau de satisfação laboral; i) todo o processo foi submetido à análise estatística -Teste $t$, ANOVA (ambas com nível de significância alfa $=0,05$ ) e Coeficiente de Correlação de Person; j) por fim, empregou-se os estudos relativos ao campo de trabaIho de Sennett $(2004,2006,2009)$ e as pesquisas produzidas na área (Tabela 1). 
Tabela 1. Resultado das Escalas Beck de Ansiedade e Depressão (BAI e BDI) da Amostra de Docentes $(n=163)$

\begin{tabular}{|c|c|c|c|}
\hline & Classificação & Frequência (n) & $\begin{array}{l}\text { Porcentagem } \\
\text { Válida (\%) }\end{array}$ \\
\hline \multirow[t]{4}{*}{$\begin{array}{l}\text { Ansiedade } \\
\text { (BAI) }\end{array}$} & $\begin{array}{c}\text { Mínimo } \\
\text { (menos de } 11 \text { pontos) }\end{array}$ & 92 & 56,4 \\
\hline & $\begin{array}{l}\text { Leve } \\
\text { (11-19 pontos) }\end{array}$ & 34 & 20,9 \\
\hline & $\begin{array}{c}\text { Moderado } \\
\text { (20-30 pontos) }\end{array}$ & 25 & 15,3 \\
\hline & $\begin{array}{c}\text { Grave } \\
\text { (31-63 pontos) }\end{array}$ & 12 & 7,4 \\
\hline \multirow[t]{4}{*}{$\begin{array}{l}\text { Depressão } \\
\text { (BDI) }\end{array}$} & $\begin{array}{c}\text { Mínimo } \\
\text { (menos de } 12 \text { pontos) }\end{array}$ & 92 & 56,4 \\
\hline & $\begin{array}{l}\text { Leve } \\
\text { (12-19 pontos) }\end{array}$ & 50 & 30,7 \\
\hline & $\begin{array}{c}\text { Moderado } \\
\text { (20-35 pontos) }\end{array}$ & 21 & 12,9 \\
\hline & $\begin{array}{c}\text { Grave } \\
\text { (36-63 pontos) }\end{array}$ & - & \\
\hline
\end{tabular}

Informa-se: o presente estudo foi aprovado pelo Comitê de Ética, CAAE $n^{\circ}$ 53311816.0.0000.5401, conforme diretrizes e normas da Resolução n $466 / 2012$ do CNS/MS.

\section{Resultados e discussão}

Os resultados evidenciaram características sociodemográficas predominantes dessa população: a) a média de idade era de 44,6 anos (a menor 23, a maior 67 e a mediana 45), estando a maioria entre 31 e 50 anos $(67,7 \%) ; b)$ a prevalência de sujeitos do sexo feminino (84\%); c) a maior parcela autodeclarada caucasiana/ branca (75,9\%); d) o predomínio de casados/união estável $(66,3 \%)$; e) a maioria com filhos (77\%); f) a quase totalidade religiosa (85,9\%) - os católicos representaram 60,1\% do total); resultados semelhantes aos obtidos por Gatti e Barreto (2009), em estudo da UNESCO sobre o perfil dos professores brasileiros.

Notadamente 23\% dos docentes apresentaram sintomas habituais encontrados em diagnósticos de transtorno de ansiedade e 13\% para depressão valores maiores que o da média mundial e o da brasileira (OMS, 2017). Com relação à incidência de educadores com sintomas depressivos, os resultados também foram maiores do que os obtidos por Inocente (2005) e E. P. Silva (2015), em amostra de docentes universitários.

Tomando por base as referidas escalas, os resultados apontaram correlação entre essas duas patologias (Person, $r=0,55$ ), ou seja, elas apresentaram interdependência moderada positiva. Esta relação foi observada também por Bodega, Bio, Zomignani, Garcia Jr. e Pereira (1995), em pesquisa realizada com pacientes hospitalares, mesmo tendo sido utilizado escala de mensuração diferente das adotadas no presente estudo. Os autores indagaram se ambas, teoricamente, não deveriam ser investigadas integradamente, apesar da relevância clínica em se distinguir as duas patologias, sobretudo no tocante à medicação. Nesse contexto, ao se analisar a proporção de docentes com sintomas de ansiedade e/ou depressão, 44 sujeitos $(27 \%)$ as apresentaram.

Sem se ater a um diagnóstico específico - ou seja, ao analisar todos aqueles que apresentaram grau leve, moderado ou grave de sintomas ansiosos ou depressivos -, os dados sugerem que $58 \%$ dos sujeitos estavam em processo de adoecimento mental. Esses resultados são maiores do que os obtidos por Carraro (2015), Gasparini et al., (2006), Ceballos e Santos (2015), Ferreira et al. (2015), Reis et al. (2005) e C. L. Souza et al. (2011).

Com relação aos tratamentos, $20,6 \%$ dos sujeitos estavam usando medicação com função psicotrópica; todavia, apenas 3,1\% eram acompanhados por psiquiatra. Supõe-se, a esse respeito, que ainda existe forte preconceito com essa área de saber, mesmo sendo a indicada para diagnóstico e tratamento de psicopatologias. Acrescente-se: ao serem questionados sobre o histórico medicamentoso, 58,9\% dos docentes já fizeram uso dessas drogas, reforçando a constatação da incidência, em níveis críticos, de sintomas ansiosos/depressivos nessa população. Os motivos apontados para o uso de citada medicação foram irritabilidade, impaciência e nervosismo (42,1\%); tristeza e desânimo (27,2\%); oscilação do humor (16,2\%); insônia (41,4\%); conduta/pensamento compulsivo (9,4\%) e alucinação/paranoia (1,3\%).

Embora 35\% dos sujeitos já tenham recebido ajuda psicológica, somente $3,7 \%$ deles estavam, na época do estudo, em tratamento psíquico. Acredita-se, como psicólogos, que a psicoterapia possibilita o fortalecimento interno e estimula a reflexão para se lidar com os conflitos vividos no dia a dia. Muitos docentes, a esse respeito, manifestaram vontade de submeterem-se à psicoterapia; contudo, não o fizeram por falta de recursos pecuniários.

Feita essa exposição, apresenta-se, a seguir, sua relação com os fatores factuais.

\section{Fatores factuais e ansiedade/depressão}

Verificou-se a existência de relação entre algumas características pessoais e profissionais dos professores com a incidência maior de sintomas ansiosos e/ou depressivos. 


\section{Idade}

Apesar do estudo de J. C. Souza e Costa (2011) sugerir que a idade menor dos docentes está ligada a melhor qualidade de vida física e de capacidade funcional, na presente pesquisa os sujeitos com idade superior a 60 anos apresentaram níveis de sintomas depressivos menores do que o observado em outras faixas etárias (ANOVA, $p=0,049$ ). Esses dados vão ao encontro das informações constantes do DSM-V (American Psychiatric Association, 2015) que, ao analisar a incidência de transtornos depressivos, por faixa etária, verificou que a população acima de 60 anos apresentava incidência menor de adoecimento.

$\mathrm{Na}$ sociedade brasileira, a chegada aos 60 anos desencadeia transformações no sujeito, pois culturalmente ele passa a pertencer à faixa etária rotulada de "terceira idade". Talvez isso possa interferir na forma como esses docentes estabelecem suas prioridades e enxergam os desafios diários. Assim, com a idade, Huberman (2000) ao analisar o ciclo de vida profissional dos professores evidenciou que certas situações geradoras de angústia deixam de fazer sentido e, em decorrência, os sujeitos tendem a dar valor a questões novas. Além disso, como são profissionais ativos, ainda não viveram o sentimento de "inutilidade" - condição apontada por Sennett (2006, 2009) como um dos maiores temores do trabalhador atual apresentados por algumas pessoas ao se aposentarem. Outra singularidade refere-se à pequena quantidade de sujeitos desse grupo ( $n=8$, isto é, $5,1 \%$ do total). Assim, embora as ferramentas estatísticas permitam cálculos com " $n$ " iguais ou maiores que 5 , essa diferença pode ter se dado ao acaso.

\section{Filhos}

Os docentes-pais de um filho, por sua vez, apresentaram maiores níveis de sintomas depressivos (ANOVA, $p=0,02$ ). Esse dado foi ao encontro do estudo de Carraro (2015), ao ter verificado maior taxa de educadores mentalmente adoecidos entre os que possuíam dependentes. Porém, no estudo em questão, não lhes foi solicitado informar se os filhos eram dependentes. Além disso, no caso dos que possuíam dois filhos, ocorreu o inverso. Foram eles, justamente, que vieram a apresentar os menores valores de sintomas depressivos. Como interpretar?

Não obstante as exigências atuais quanto ao estabelecimento de ligações superficiais e flexíveis, para Sennett (2009), "as pessoas sentem falta de relações humanas constantes e objetivos duráveis" (p. 117). Por vezes, um filho demanda muita atenção e energia.
Não se refere aqui ao cuidado e ao afeto depositado nele e que se mantém ao longo da vida. Contudo, o excesso de estímulos, a exigir respostas imediatas levando, em consequência, ao desgaste mental - atrapaIha ou impede as tentativas de manter tal vínculo. Em decorrência, amiúde, a paternidade adoece os que não conseguem conciliá-la com o seu ritmo de vida. Quando há um segundo filho, os pais já possuem experiência, a ponto de o desgaste mental ser consideravelmente menor (Rapoport \& Piccinini, 2011).

\section{Religião}

No que concerne às tentativas de construção de histórias de longo prazo, acreditou-se ainda ter sido esse o motivo para os religiosos terem apresentado menores níveis de sintomas ansiosos e depressivos (Teste $\mathrm{t}, p=$ 0,005 e $p=0,049$, respectivamente). Apesar da bibliografia atinente à saúde mental do professor não ter verificado essa relação, há estudos, como o de MoreiraAlmeida, Lotufo-Neto e Koening (2006), que encontraram associação entre saúde psíquica e fé. Afinal, esta continua a ser um dos poucos investimentos a não se esperar retorno imediato, pois a premiação se dá depois da morte (salvação, paraíso, evolução).

Outros pontos também podem ser considerados, tais como: a) ela possibilita a vivência em ambiente de socialização e de sentimento de pertença. Para Sennett (2004, 2009), esses aspectos são importantes em um mundo de relações fugazes, pois o grupo religioso funciona como rede afetiva, auxiliando na superação e/ ou na convivência com o adoecimento mental. Nesse sentido, talvez os templos religiosos sejam um dos poucos "lugares" cuja sociedade tem se comportado como comunidade, pois os seus membros compartiIham dos mesmos objetivos, apresentam mecanismos de preservação e proteção recíproca (Cortella \& La Taille, 2005); b) proporciona conforto, por oferecer um sentido para a vida. Isso explicaria, em parte, o fato de os religiosos (praticantes ou não) manterem diferença estatística significativa sobre os "sem religião"; c) em uma sociedade estimuladora do narcisismo e da heteronomia, a religião torna-se produtora de algumas condutas (generosidade, por exemplo), auxiliando na melhoria da qualidade de vida (La Taille, 1992; Pedro-Silva, 2005; Piaget, 1932/1994).

\section{Capacitação Profissional (Escolaridade)}

Quanto à capacitação profissional, os questionados foram largamente submetidos à qualificação técnica, o que contraria Simplício e Andrade (2011) que, 
em seu estudo, atribuíram o pouco acesso a cursos um dos motivos para o adoecimento docente. Baseou-se essa constatação no fato de $76,7 \%$ possuírem pós-graduação ou uma segunda graduação. Averiguou-se que os possuidores de mais de um diploma apresentavam níveis superiores de sintomas depressivos (Teste $t$, $p=0,008$ ). Esse fato não se repetiu entre os pós-graduados, apesar de ter sido pequena a margem (Teste $t$, $p=0,058$ ) para serem classificados como comprometidos pelas patologias em análise. Como a quase totalidade já havia concluído mais de um curso, descartou-se a hipótese de essa diferença ter sido por causa de um possível desgaste mental decorrente da conciliação entre trabalho e estudos formais.

Talvez esse grupo tenha sentido mais fortemente as cobranças de aprimoramento técnico, pois a área de atuação continuava a mesma (o magistério). Sennett (2006), a esse respeito, afirmou ser o novo imperativo pedagógico e trabalhista fazer algo novo, em vez de aplicar o aprendido. Assim, a perícia (capacidade de fazer algo bem feito, apenas por fazer) perdeu o seu mérito para outros atributos - criatividade, eficiência, inovação, produtividade e protagonismo (não dependendo de exigências feitas por chefias, pois se espera que elas sejam "invisíveis").

Conforme observações feitas por Pedro-Silva (2002) e Ferreira-Costa (2017), muitos docentes acabavam buscando capacitar-se para melhorar o salário, ter a opção de escolher a escola na qual desejavam trabalhar e para progredir na carreira docente. Assim, nesse caso, a formação não foi movida pelo desejo de enriquecimento intelectual, mas como forma de obtenção de status financeiro/ social, aspectos enfatizados pelo clima cultural vigente. Essa situação pode ter auxiliado para o adoecimento dos docentes. Para Elias (2014), ao querer mais, eles acabaram, na mesma medida, se angustiando mais, pois o capitalismo estimula o consumismo e, como corolário, a insatisfação desmedida passa a fazer parte do psiquismo.

\section{Vínculo com o Trabalho}

Há, ainda, a falta de estímulo para a construção de ligações "fortes" e duradoras, segundo Sennett (2006). A esse respeito, os docentes que lecionavam em apenas uma escola apresentaram graus maiores de sintomas ansiosos e depressivos (Teste t, $p=0,04 \mathrm{e}$ $p=0,02)$. Esse resultado parece ter influenciado no fato de os professores das escolas integrais pertencerem, na quase totalidade, a esse grupo. Essa assertiva parte da observação que, ao desconsiderar os professores de escola integral, ocorreu diminuição da discrepância de pontuação entre o grupo formado por professores que trabalhava em apenas uma escola e o que lecionava em duas ou mais, fazendo com que a diferença deixasse de ser estatisticamente significativa.

Inicialmente, julgava-se que o desgaste físico de deslocamento entre as escolas poderia ter influenciado para um maior cansaço mental, como conjecturaram Simplício e Andrade (2011). Todavia, alguns docentes a seguir essa rotina disseram preferi-la, pois, assim, não restava tempo para se afligirem com os problemas de cada lugar. Em especial nas escolas de regime integral, houve queixas sobre o desgaste gerado em decorrência do longo período de tempo dispendido no mesmo local (40 horas semanais). Apontada, entre outros, por Sennett $(2004,2009)$, a efemeridade acabou se convertendo em mecanismo de defesa, diante de um mundo cuja formação de vínculo é julgada démodé.

\section{Organização Escolar}

A seguir, foram abordados fatores da organização escolar considerados pela literatura como fontes para o adoecimento, bem como a realidade vivida pelos sujeitos da pesquisa.

No início, notou-se que os docentes apresentadores de mais sintomas de ansiedade e depressão eram os menos satisfeitos com o trabalho em quase todos os itens examinados, validando os resultados obtidos por Ceballos e Santos (2015) e C. L. Souza et al. (2011), ao apontarem a interferência dessas doenças na relação dos docentes com seu meio laboral.

Esses dados permitiram considerar duas hipóteses não excludentes: a) os dados sustentam as conclusões apontadas na literatura, isto é, as condições para o exercício profissional, apresentadas a seguir, são fatores que parecem influenciar para a ocorrência de sintomas de adoecimento mental nos docentes; b) os elementos coletados reforçam as orientações de Dalgalarrondo (2008) referentes às patologias objetos do presente estudo. Autor e órgão caracterizam a depressão como uma doença que leva o paciente a construir uma visão negativa acerca do mundo. Essa situação é partilhada, em parte por aqueles com transtorno de ansiedade, por causa da sensação prolongada de perigo que vivenciam, aliada a outros traços comuns com a depressão (como irritabilidade e impaciência).

Assim, nota-se que o processo de adoecimento é uma via de "mão dupla". A escola possui especificidades causadoras de elevado desgaste mental nos educadores, provocando a enfermidade (Ceballos \& Santos, 2015; C. L. Souza et al., 2011). Este estado, por sua vez, 
impede a capacidade dos docentes de enfrentarem o cenário acertadamente, tolhendo suas defesas internas e os impedindo de encontrar soluções (Lyra, Assis, Njaine, \& Pires, 2013). Identificou-se esse padrão, ao se constatar que, embora identificassem os incômodos, não foram localizados na literatura estudos sobre ações dos próprios professores visando à promoção da saúde.

Quanto ao ambiente laboral, a falta de estrutura físico/material adequada foi citada como fator de adoecimento psíquico por Ferreira et al. (2015), Gasparini et al. (2006), E. P. Silva (2015), Silveira et al. (2011) e J. C. Souza e Costa (2011). Todavia, no presente estudo, $59,4 \%$ dos sujeitos estavam satisfeitos com esse ambiente.

A esse respeito, constatou-se: todas as escolas, nas quais a pesquisa foi realizada, possuíam quantidade de salas de aula adequada para a sua demanda, laboratórios, quadra poliesportiva, biblioteca, sala de professores, entre outros espaços. Apesar de serem construções antigas, estavam pintadas, com quase nenhuma presença de pichações e possuíam áreas abertas para a circulação de ar e de pessoas. Dessa forma, embora os referidos estudiosos tenham apontado o ambiente laboral como influenciador no adoecimento psíquico (Teste $t$, $p=0,0001$, para ansiedade e depressão), a realidade encontrada mostrou-se, ao menos aparentemente, adequada para o desenvolvimento da ação educativa.

No entanto, a situação foi oposta quando eles foram questionados acerca dos materiais pedagógicos. A maioria os desaprovou $(59,4 \%)$, sendo esta a questão a apresentar maior relação com os sintomas ansiosos (Teste $t$, $p=5,89 \times 10^{-5}$ ) e depressivos (Teste $t, p=7,86 \times 10^{-8}$ ). A discrepância foi maior nas instituições de meio período $(64,8 \%)$ do que nas integrais $(49,1 \%)$. Mesmo estas unidades integrais tendo à disposição mais recursos dessa natureza, em ambas os discursos foram parecidos. Na devolutiva, a principal queixa referia-se à ausência ou à escassez de ferramentas fora das tradicionais ("lousa e giz"), como a insuficiência de recursos de multimídia. Verificou-se, assim, que os docentes desejavam ter uma gama maior de estratégias para "despertar" o interesse dos alunos pelo aprendizado. À vista disso, a necessidade de flexibilidade no processo de ensino-aprendizagem pode ter deixado os docentes mais inseguros, pois não era possível serem postas em prática por causa da falta de recursos. Nessa lógica, uma didática "limitada" pela ausência desses meios pode, para os alunos, ter tornado a aula mais enfadonha. Conforme Pedro-Silva (2005), esse tema apresenta-se relevante, pois o interesse do alunado é um dos requisitos para os docentes comporem relação respeitosa com esse público, a ponto de equacionar um de seus maiores temores: a indisciplina.

Um dos temas abordados por Sennett (2004) refere-se à construção do respeito e da capacidade de envolvimento com outrem em um mundo economicamente desigual, como o atual: "a sociedade moderna carece de expressões positivas de respeito e reconhecimento pelos outros" (p. 13). Considerando-se o fato de a escola ser habitada por vários atores (docentes, funcionários/gestores, alunos e suas famílias), estes sujeitos compõem uma complexa rede, formando alianças entre si para garantir, em tese, o funcionamento desse lugar. A construção do respeito e de vínculos "saudáveis" é, assim, essencial para se alcançar esse objetivo.

No presente estudo, constatou-se a fragilidade de alguns desses laços, sobretudo entre os profissionais da escola, os alunos e seus responsáveis. Já entre os professores e entre eles e os gestores, os sujeitos apontaram alto índice de aprovação (respectivamente, 71,9\% e $75,5 \%$ ). Deste grupo e dos demais empregados, $68,5 \%$ eram apreensivos quanto ao bom andamento da escola. Tal situação levou a crer que os docentes estavam satisfeitos com a organização "pessoal" do trabalho, pois se declararam companheiros e implicados com seus colegas, além de confiarem em suas lideranças - o aspecto mais bem avaliado.

Esses tópicos são essenciais à garantia da promoção de saúde mental no trabalho escolar, segundo Elias (2014), Gasparini et al., (2006), Silveira et al. (2011) e Simplício e Andrade (2011). Os pesquisadores compartilharam desse raciocínio, pois se verificou associação entre aumento dos níveis de sintomas de ansiedade e de depressão naqueles que disseram não estabelecer bom diálogo com a direção/coordenação (Teste $t$, $p=0,03$ e $p=0,01$ ). A presença de sintomas depressivos foi ainda maior nos detentores de pior relação com os outros docentes (Teste $t, p=0,03$ ) ou que viram descompromisso da equipe (Teste $t, p=0,02$ ).

$\mathrm{Na}$ sequência, discorreu-se sobre a relação problemática entre a escola, os estudantes e seus responsáveis. Para os inquiridos, os alunos não possuíam interesse pelas aulas (70,2\%), eram desrespeitosos $(67,5 \%)$ e os familiares pouco se interessavam em conduzir a vida acadêmica dos seus filhos (84,1\%), além de cobrarem em excesso e serem agressivos quando chamados, a ponto de os docentes não se verem respeitados por eles $(51,6 \%)$. Essa desaprovação talvez não fosse maior pela própria distância entre familiares e escola (sequer criavam vínculo). 
Essa conjuntura tornou-se preocupante pelos seguintes motivos: a) diferentemente dos aspectos já citados, essa realidade se mostrou inadequada para a maioria dos docentes, pois os problemas de interação com estudantes e seus responsáveis faziam parte da vivência de todas as escolas. Tanto é que a indisciplina dos educandos foi a queixa mais frequente dos docentes, por ocasião da devolutiva. Alguns chegaram a dizer: a depender da sala onde lecionariam, já não dormiam bem no dia anterior. Embora presente em todos os níveis de ensino, esse discurso foi mais intenso entre os que davam aulas no Ensino Médio. Em contrapartida, as queixas quanto à postura dos pais foram mais citadas pelos docentes dos anos iniciais do Ensino Fundamental; b) essa dinâmica afeta a saúde mental dos docentes, assim como referido por Costa (2014), Elias (2014), Ferreira et al. (2015), Simplício e Andrade (2011), entre outros.

Constatou-se, ainda: os mais depressivos manifestaram maior descontentamento por causa do desrespeito demonstrado pelos educandos (Teste $t, p=0,01$ ), do desinteresse deles (Teste $t, p=0,02$ ) e de seus responsáveis pelo ato educativo (Teste $t, p=0,004$ ).

No tocante ao respeito dispensado pelos familiares aos docentes, não houve significativa diferença estatística, tendo como variável os níveis de sintomas ansiosos e depressivos. Isso pode ser explicado pela ausência parental nesse ambiente, como já mencionado. A propósito, a ansiedade não influenciou ou foi influenciada pelo grau de satisfação nesses itens.

De certo, como afirmou Sennett (2006), é maior a possibilidade de criação de vínculos duradouros e a construção de narrativas de longo prazo com os colegas de profissão, pois tendem a permanecer constantes no decorrer do tempo - diferentemente dos estudantes, que mudam ao início de cada ano letivo. Porém, a discrepância entre a qualidade da conexão criada pela equipe escolar e a com o alunado e seus responsáveis deve ser vista com cautela. Ao mesmo tempo que se pode concluir ser o companheirismo, nesses espaços, aspecto a funcionar como mecanismo de proteção diante dos desafios da prática docente, indagou-se: Essa autoavaliação positiva não está atribuindo os problemas da escola a fatores externos?

Em todo caso, mesmo admitindo, como Costa (2014) e Inocente (2005), que o prestígio social do educador diminuiu com o passar dos anos - afetando na forma como as pessoas interagem com essa profissão -, julgou-se inquietante a visão negativa nutrida pelos docentes no tocante aos alunos/responsáveis.
Não simpatizar com eles é, ao mesmo tempo, admitir não gostar de seu objeto de trabalho. $E$ isso gera adoecimento, conforme Gasparini et al. (2006) e Simplício e Andrade (2011).

Outro aspecto referiu-se a uma das principais características do capitalismo atual: a forma como as instituições se apropriaram do tempo de seus funcionários. O flexitempo (Sennett, 2009) se refere a essa nova dinâmica do trabalho, onde espaço e tempo são flexíveis. Dessa forma, uma tarefa pode ser executada na organização ou na casa do empregado, não importando mais as horas de serviço, mas as metas cumpridas. Essa flexibilização, ao invés de dar mais liberdade, acabou aprisionando o sujeito ao trabalho, tornando-o onipresente em sua vida (ainda mais com o uso de smartphones).

No magistério, essa relação sempre existiu e foi motivo de queixa entre os docentes, como apontaram Carraro (2015) e Silveira et al. (2011). Para esses autores, a falta de tempo para a conclusão de seus deveres profissionais era um dos fatores responsáveis pelo adoecimento psíquico dos educadores.

Os resultados obtidos foram parecidos aos desses autores. A maioria dos sujeitos não estava satisfeita com o tempo disposto para apresentar todo o conteúdo programático em aula (51,3\%). A desaprovação foi maior quando se averiguou o tempo disponível para o preparo das aulas (66,2\%). Era frequente a necessidade de concluí-las fora do horário de expediente, mesmo sendo propiciadas "horas de estudo" ao preparo das matérias/correção das atividades.

Essa dificuldade em regular o tempo do trabalho, a ponto de ele invadir a vida pessoal do docente, pode ter prejudicado a sua qualidade de vida. Tal afirmação, além da literatura, apoiou-se no fato de se ter aferido que os sintomas de ansiedade/depressão foram maiores naqueles que sentiam na "pele" a falta de tempo para preparar (Teste $t, p=0,01$ e $p=0,001$ ) e ministrar os conteúdos das aulas (Teste t, $p=0,0001$ e $p=6,8 \times 10^{-7}$ ). Julgou-se esse resultado inquietante, pois referida falta é a única a afetar, ao mesmo tempo, os níveis de sintomas ansiosos e depressivos, além de ser uma questão que acomete a maioria dos sujeitos. Com base em Sennett (2004, 2006, 2009), isso ocorreu porque o tempo influencia em todos os aspectos da vida do trabalhador, desde a formação de vínculos duradouros, até a qualificação profissional. Assim, sua ausência fragilizou essas relações e impediu a capacitação para os desafios diários.

Quanto às expectativas ao se formar professor, a não realização dos desejos afetou a saúde psíquica 
dos indagados, corroborando com os estudos de Elias (2014), E. P. Silva (2015) e Simplício e Andrade (2011). Esse descontentamento se refletiu na pesquisa, pois $51,2 \%$ estavam insatisfeitos ou pouco satisfeitos com o rumo da carreira e, nesse grupo, houve maior ocorrência de condutas ligadas à ansiedade (Teste $t, p=0,0008$ ). Por outro lado, contrariando a suspeita dos autores, a depressão não influenciou nas respostas. Julgava-se que os participantes apresentadores de maiores níveis de sintomas depressivos seriam mais críticos, em razão da visão negativa que, amiúde, têm em relação a si e ao mundo. Talvez esses resultados decorram da maneira como depressivos e ansiosos se enxergam. Nos primeiros, em virtude do caráter autodepreciativo da patologia, a admissão de que não estão realizados profissionalmente pode ser vista como atestado de não serem "bons" educadores, inibindo - por causa do sentimento de vergonha - juízos negativos (La Taille, 2002). Por outro lado, nos ansiosos, apesar de a insatisfação ser nutrida, em parte, pela sensação de insegurança vivida na escola, a percepção de perigo pode ser atribuída a fatores externos ao professor, não os colocando em posição de inquirirem a própria capacidade, gerando menos estratégias de defesa ao responder a esse respeito.

O salário pode ter sido outro ingrediente a influenciar nessa decepção, validando Inocente (2005) e Simplício e Andrade (2011). O predomínio dos insatisfeitos com o salário $(71,1 \%)$ mostrou que eles se concebiam desvalorizados. É certo: a satisfação profissional não se resume a se ter um salário razoável; porém, na atual sociedade, o prestígio é medido por essa variável (La Taille, 2005). Assim, o desgaste mental, sem retorno pecuniário adequado, pode ter sido um dos responsáveis pelo sofrimento dessas pessoas, pois foram os docentes os menos satisfeitos com o salário a apresentar maior quantia de sintomas depressivos (Teste $t, p=0,03$ ).

Os resultados apontaram, ainda, que grande parcela dos docentes estava infeliz com a profissão e isso estava afetando em demasia a sua saúde, sobretudo a mental.

\section{Considerações finais}

Alguns dados obtidos neste trabalho foram contrários aos verificados em outros estudos, como, por exemplo, os sujeitos tinham uma visão positiva referente à estrutura física das escolas e boa relação com a equipe escolar. Porém, outros itens foram ao encontro dos estudos realizados acerca da temática, como o problema da dificuldade de interação com o alunado/seus responsáveis e o da falta de tempo para a execução de suas funções.

Conforme Sennett (2006) e Elias (2014), a efemeridade das relações contemporâneas, aliado à dinâmica trabalhista de curto prazo, à competitividade e à produtividade, tem desestimulado, atualmente, o docente à construção de estratégias, objetivando o estabelecimento de vínculos de longo prazo. Desse modo, quando há a necessidade de se construir vínculos mais profundos - como na relação docente/educandos -, o desgaste mental costuma ser considerável.

A percepção é a de se estar vivendo hoje em uma sociedade cujas pessoas estão no "limite". Ao refletir sobre as fontes do esgotamento mental, nada exige mais do que lidar com outrem, em razão, entre outros fatores, dos sentimentos gerados nessas relações. Posto isto, o magistério pode ser visto como uma das carreiras psicologicamente mais desgastantes, com o agravante de que o docente já não possui, nos dias atuais, o ânimo de que outrora os mestres dispunham para a execução de seu trabalho.

Assim, não foi a formação "deficitária" e/ou insuficiente desses profissionais, pois a população estudada tinha mais de uma formação em nível superior e/ou fez pós-graduação. Pode-se considerar, porventura, a desvalorização da profissão de magistério, pois os docentes se queixaram do salário, além de se sentirem desrespeitados pelos alunos e responsáveis. Supõe-se, ainda, o fato de os docentes terem sido "tragados" pela atual cultura, a qual estimula a superficialidade, a intempestividade, a diversão pela diversão, o hedonismo, a confusão do mundo "real" com o virtual, a volta do misticismo e das interpretações fundamentalistas. Julga-se, portanto, que a educação deve trabalhar nesse "espaço", ou seja, nas imprecisões e contradições destes aspectos com os objetivos educacionais.

\section{Referências}

Adorno, T. W., Frenkel-Brunswik, E., Levinson, D. J., \& Sanford, R. N (1950). The authoritarian personality. Nova lorque: Harper \& Row.

American Psychiatric Association (2015). Manual diagnóstico e estatístico de transtornos mentais: DSM-V. Porto Alegre: Artmed.

Bauman, Z. (1997). O mal-estar da pós-modernidade. Rio de Janeiro: Jorge Zahar Editor.

Beck, A. T., Brown, G., Epstein, N., \& Steer, R. A. (1988). An inventory for measuring clinical anxiety: Psychometric properties. Journal of Consulting and Clinical Psychology, 56(6), 893-897. doi: 10.1037/0022-006X.56.6.893 
Beck, A. T., Erbaugh, J., Mendelson, M., Mock, J., \& Ward, C. H. (1961). An inventory for measuring depression. Archives of General Psychiatry, 4(6), 561-571. doi: 10.1001/archpsyc. 1961.01710120031004

Bodega, N. J., Bio, M. R., Zomignani, M. A., Garcia Junior, C., \& Pereira, W. A. B. (1995). Transtornos do humor em enfermaria de clínica médica e validação de escala de medida (HAD) de ansiedade e depressão. Revista de Saúde Pública, 29(5), 355-363. doi: 10.1590/S0034-89101995000500004

Carraro, M. M. (2015). Condições de trabalho e transtornos mentais comuns em professores da rede básica municipal de ensino de Bauru-SP (Dissertação de Mestrado, Universidade Estadual Paulista, Botucatu). Recuperado de http://hdl.handle.net/11449/131936

Ceballos, A. G. C., \& Santos, G. B. (2015). Fatores associados à dor muscoesquelética em professores: aspectos sociodemográficos, saúde geral e bem-estar no trabalho. Revista Brasileira de Epidemiologia, 18(3), 702-715. doi: 10.1590/1980-5497201500030015

Codo, W. (Org.). (1999). Educação: carinho e trabalho. Rio de Janeiro:Vozes.

Cortella, M.S., \& La Taille, Y de. (2005). Nos labirintos da moral.Campinas, SP: Papirus.

Costa, L. S.T. (2014). Avaliação da síndrome de Burnout em professores universitários de Piracicaba-SP (Tese de Doutorado, Universidade Estadual de Campinas, Piracicaba). Recuperado de http://repositorio. unicamp.br/jspui/handle/REPOSIP/289937

Cunha, J. A. (2011). Manual das Escalas Beck. São Paulo:Casa do Psicólogo.

Dalgalarrondo, P. (2008). Psicopatologia e semiologia dos transtornos mentais. Porto Alegre: Artmed.

Elias, M. A. (2014). Equilibristas na corda bamba: o trabalho e a saúde de docentes do ensino superior privado em Uberlândia/MG (Tese de Doutorado, Universidade de São Paulo, Ribeirão Preto). doi: 10.11606/T.59.2014.tde-12122014-104307

Ferreira, R. C., Silveira, A. P., Sá, M. A. B., Feres, S. B. L., Souza, J. G. S., \& Martins, A. M. E. B. L. (2015). Transtorno mental e estressores no trabalho entre professores universitários da área da saúde. Trabalho, Educação e Saúde, 13(1), 135-155. doi:10.1590/1981-7746-sip00042

Ferreira-Costa, R. Q. (2017). O mundo do trabalho docente e o esgotamento psíquico (Dissertação de Mestrado, Faculdade de Ciências e Letras, Universidade Estadual Paulista, Assis, São Paulo). Recuperado de http://hdl.handle.net/11449/151000

Gasparini, S. M., Barreto, S. M., \& Assunção, A. A. (2006). Prevalência de transtornos mentais comuns em professores da rede municipal de Belo Horizonte. Cadernos de Saúde Pública, 22(12), 2679-2691. doi: 10.1590/S0102-311X2006001200017

Gatti, B. A., \& Barreto, E. S. S. (Coord.) (2009). Professores no Brasil: impasses e desafios. Brasília: Unesco.

Gomes, R. K., \& Oliveira, V. B. (2013). Depressão, ansiedade e suporte social em profissionais de enfermagem. Boletim de Psicologia, 63(138), 23-33. Recuperado de http://pepsic.bvsalud.org/scielo. php?script=sci_arttext\&pid=S0006-59432013000100004\&lng=pt\&tlng=pt

Huberman, M. (2000). O ciclo de vida profissional dos professores. In A. Nóvoa (Org.), Vidas de professores (pp. 31-61). Porto: Porto.

Inocente, N. J. (2005). Síndrome de Burnout em professores universitários do Vale do Paraíba (SP) (Tese de Doutorado, Universidade Estadual de Campinas, Campinas). Recuperado de http://repositorio.unicamp. br/jspui/handle/REPOSIP/311898

Jacques, M. G. C. (2003). Abordagens teórico-metodológicas em saúde /doença mental \& trabalho. Psicologia \& Sociedade, Belo Horizonte, 15(1), 97-116. doi: 10.1590/S0102-71822003000100006
La Taille, Y. (1992) (Org.). Piaget, Vygotsky, Wallon. São Paulo: Summus La Taille, Y. (2002). Vergonha: a ferida moral. Petrópolis (RJ): Vozes.

La Taille, Y. (2005). A escola e os valores: a ação do professor. In Y. de La Taille, N. Pedro-Silva, \& J. S. Justo (Orgs.), Indisciplina/disciplina: ética, moral e ação do professor (pp. 5-21). Porto Alegre: Mediação.

La Taille, Y. (2009). Formação ética: do tédio ao respeito de si. Porto Alegre: Artmed.

Laurell, A. C., \& Noriega, M. (1989). Processo de produção e saúde: trabalho e desgaste operário. São Paulo: Hucitec.

Lyra, G. F. D., Assis, S. G., Njaine, K., \& Pires, T. O. (2013). Sofrimento psíquico e trabalho docente - implicações na detecção de problemas de comportamento em alunos. Estudos e Pesquisas em Psicologia, 13(2), 724-744. Recuperado de http://pepsic.bvsalud.org/scielo. php?script=sci_arttext\&pid=S180842812013000200017\&lng=pt\&nrm=iso

Moreira-Almeida, A., Lotufo-Neto, F., \& Koening, H. G. (2006). Religiosidade e saúde mental: uma revisão. Revista Brasileira de Psiquiatria, 28(3), 242-250. doi: 10.1590/S1516-44462006005000006

Oliveira, G. N. M., Araujo Filho, G. M., Kummer, A., Salgado, J. V., Portela, E. J., Sousa-Pereira, S. R., \& Teixeira, A. L. (2011). Inventário de depressão de Beck (BDI) e escala de avaliação de depressão de Hamilton (HAM-D) em pacientes com epilepsia. Revista Brasileira de Psiquiatria, 60(2), 131-134. doi: 10.1590/S0047-20852011000200008

Organização Mundial de Saúde. (2017). Depression and other common mental disorders: global health estimates. Genebra: World Health Organization.

Pedro-Silva, N. (2002). Ética, indisciplina \& violência nas escolas. Petrópolis (RJ): Vozes.

Pedro-Silva, N. (2005). Ética, (in)disciplina e relação professor-aluno. In Y. La Taille, N. Pedro-Silva \& J. S. Justo (Orgs.), Indisciplina/ disciplina: ética, moral e ação do professor (pp.55-95). Porto Alegre: Mediação.

Pereira, J. A. (2015). Trabalho docente e sofrimento mental (Dissertação de Mestrado, Universidade Estadual Paulista, Franca). Recuperado de http://hdl.handle.net/11449/127715

Piaget, J. (1994). O juízo moral na criança. São Paulo: Summus. (Obra original publicada em 1932)

Rapoport, A., \& Piccinini, C. A. (2011). Maternidade e situações estressantes no primeiro ano de vida do bebê. Psico-USF, 16(2), 215-225. doi: 10.1590/S1413-82712011000200010

Reis, E. J. F. B., Carvalho, F. M., Araújo, T. M., Porto, L. A., \& SilvanyNeto, A. M. (2005). Trabalho e distúrbios psíquicos em professores da rede municipal de Vitória da Conquista, Bahia, Brasil. Cadernos de Saúde Pública, 21(5), 1480-1490. doi: 10.1590/ S0102-311X2005000500021

Seligmann-Silva, E. (2011). Trabalho e desgaste mental: o direito de ser dono de si mesmo. São Paulo: Cortez.

Sennett, R. (2004). Respeito. Rio de Janeiro: Record.

Sennett, R. (2006). A cultura do novo capitalismo. Rio de Janeiro: Record.

Sennett, R. (2009). A corrosão do caráter. Rio de Janeiro: Record.

Silva, E. P. (2015). Adoecimento e sofrimento de professores universitários: dimensões afetivas e ético-políticas. Psicologia: Teoria e Prática, 17(1), 61-71. Recuperado de http://pepsic.bvsalud.org/scielo. php?script=sci_arttext\&pid=S1516-36872015000100006\&lng=pt\&tlng=pt

Silva, R. R. D. (2015). Sennett \& a Educação. Belo Horizonte: Autêntica.

Silveira, R. E.; Reis, N. A.; Santos, A. S., \& Borges, M. R. (2011). Qualidade de vida de docentes do ensino fundamental. Revista de Enfermagem, 
Ansiedade e depressão: o mundo da prática docente e o adoecimento psíquico

3(4), 115-123. Recuperado de http://www.scielo.mec.pt/scielo. php?script=sci_arttext\&pid=S0874-02832011000200012\&lng=pt\&tlng=pt

Simplício, S. D., \& Andrade, M. S. (2011). Compreendendo a questão da saúde dos professores da rede pública municipal de São Paulo. Psico, 42(2), 159-167. Recuperado de http://revistaseletronicas. pucrs.br/revistapsico/ojs/index.php/revistapsico/article/view/7566

Souza, C. L.; Carvalho, F. M.; Araújo, T. M.; Reis, E. J. F. B.; Lima, V. M C., \& Porto, L. A. (2011). Fatores associados a patologias de pregas vocais em professores. Revista de Saúde Pública, 45(5), 914-921. doi: 10.1590/S0034-89102011005000055

Souza, J. C., \& Costa, D. S. (2011). Qualidade de vida de uma amostra de profissionais de educação física. Jornal Brasileiro de Psiquiatria, 60(1), 23-27, 2011. doi: 10.1590/S0047-20852011000100005

Vicente, D. (2015). Desgaste mental de assistentes sociais: um estudo na área da habitação. Serviço Social \& Sociedade, 123(1), 562-581. doi: 10.1590/0101-6628.037

Rodney Querino Ferreira-Costa, Mestre em Psicologia pela Universidade Estadual Paulista (UNESP), é Professor do curso de Psicologia da Faculdade Anhanguera de São José dos Campos (SP). Endereço para correspondência: Rua Santa Clara, 350, apto 193, Vila Adyana, São José dos Campos (SP). Telefone: (12) 99104-3678.

E-mail: rodney2112@gmail.com

Nelson Pedro-Silva, Doutor em Psicologia Escolar e do Desenvolvimento Humano pelo Instituto de Psicologia da Universidade de São Paulo (USP), é Professor Doutor do Departamento de Psicologia Social e Educacional da Faculdade de Ciências e Letras da Universidade Estadual Paulista (UNESP). E-mail: nelsonp1@terra.com.br

Recebido em 01.jun.2018 Revisado em 08.mai.2019 Aceito em 14.mai.2019 